УДК

\title{
УСИЛИВАЮЩАЯ ЗТ ЯЧЕЙКА ЕDRАМ ПАМЯТИ С УЛУЧШЕННЫМИ ПАРАМЕТРАМИ ЧТЕНИЯ И УДЕРЖАНИЯ ДАННЫХ
}

\author{
ВАРШНИ Т., КХАНДЕЛВАЛ С., АКЕШЕ С. \\ ІТМ университет, \\ Индия, Гвалиор
}

\begin{abstract}
Аннотация. Представлена ячейка динамической оперативной памяти DRAM (Dynamic Random Access Memory) на трех транзисторах (3T), с уменьшенными шумом, статической мощностью и напряжением удержания данных DRV (data retention voltage). Указанные параметры в предложенной ячейке улучшены путем подсоединения истока запоминающего элемента к RWL шине (Read Word Line) вместо напряжения питания. Как известно, потребляемая мощность играет важную роль при проектировании сверхбольших интегральных схем (СБИС) и входит в число основных проблем отрасли производства полупроводниковых кристаллов. С целью поддержания эффективности выполнения операции записи получено пониженное значение DRV и увеличено время хранения ячейки eDRAM при помощи разработанной схемы, названной «форсированной усиливающей 3T ячейкой eDRAM-памяти». Предложенный тип ячейки eDRAM использует RWL шину посредством трех $p$-канальных MOS транзисторов (PMOS), вместо $n$-канальных MOS транзисторов (NMOS). PMOS транзисторы являются предпочтительными, поскольку обладают намного меньшим током утечки затвора, что обеспечивает лучшие результаты для удержания данных и увеличивает время хранения ячейки. Результаты проведенного моделирования получены с помощью программного пакета Cadence Virtuoso Tool при использовании 45 нм технологии для предложенной модели. На основании моделирования сделан вывод, что по сравнению с обычной усиливающей ячейкой еDRAM-памяти параметры предложенной ячейки существенно улучшены: статическая мощность составляет 0,767 пВт, напряжение DRV равно $142,009 \mathrm{MB}$, шум составляет $8,421 \mathrm{HB} / \Gamma^{1 / 2}$
\end{abstract}

Ключевые слова: eDRAM; удержание данных; усиливающая 3Т ячейка; увеличенный запас хранения; мощность утечки; нанотехнология

\section{1. ВСТУПЛЕНИЕ}

Полупроводниковая память - один из наиболее полезных строительных блоков СБИС, который представляет собой электронное устройство для хранения информации в двоичном виде и обычно используется для компьютерной памяти [1]. Чтобы поддерживать исторический рост производительности кристаллов, разработчики должны находить такие решения для устройств памяти, которые позволят достичь малой статической мощности и высокого быстродействия.

Статическая оперативная память SRAM (Static Random Access Memory) представляет собой традиционный выбор для реализации встраиваемых устройств памяти благодаря

* Работа выполнена при поддержке университета ITM Gwalior при сотрудничестве с компанией Cadence System Design, Бангалор, Индия. 